\title{
Long-term survival in spinal cord injury: a fifty year investigation
}

\author{
HL Frankel ${ }^{1}$, JR Coll ${ }^{2}$, SW Charlifue ${ }^{2}$, GG Whiteneck ${ }^{2}$, BP Gardner ${ }^{1}$, MA Jamous ${ }^{1}$, KR Krishnan ${ }^{3}$, I Nuseibeh ${ }^{1}$, \\ G Savic $^{1}$ and P Sett ${ }^{3}$ \\ ${ }^{1}$ National Spinal Injuries Centre, Stoke Mandeville Hospital, Aylesbury, Buckinghamshire, UK; ${ }^{2}$ Craig Hospital, \\ Englewood, Colorado, USA; ${ }^{3}$ Northwest Regional Spinal Injuries Centre, Southport, Merseyside, UK
}

\begin{abstract}
The aims of this study were to examine long-term survival in a population-based sample of spinal cord injury (SCI) survivors in Great Britain, identify risk factors contributing to deaths and explore trends in cause of death over the decades following SCI. Current survival status was successfully identified in $92.3 \%$ of the study sample. Standardised mortality ratios (SMRs) were calculated and compared with a similar USA study. Relative risk ratio analysis showed that higher mortality risk was associated with higher neurologic level and completeness of spinal cord injury, older age at injury and earlier year of injury. For the entire fifty year time period, the leading cause of death was related to the respiratory system; urinary deaths ranked second followed by heart disease related deaths, but patterns in causes of death changed over time. In the early decades of injury, urinary deaths ranked first, heart disease deaths second and respiratory deaths third. In the last two decades of injury, respiratory deaths ranked first, heart related deaths were second, injury related deaths ranked third and urinary deaths fourth. This study also raises the question of examining alternative neurological groupings for future mortality risk analysis.
\end{abstract}

Keywords: mortality; spinal cord injury; survival analysis

\section{Introduction}

Long-term survival following spinal cord injury (SCI) has received a great deal of attention in recent years. An excellent review of the literature and comprehensive study of SCI survival using data from the US Spinal Cord Injury Model Systems ${ }^{1}$ describes the changes over the past 20 years in survival and causes of death. The majority of previous studiues have been limited by sample selection biases, ${ }^{2,3}$ the inclusion of early posttraumatic deaths, ${ }^{2,4,5}$ and fairly short follow-up periods, ${ }^{6}$ while a few studies have addressed survival in the third and fourth decades following injury. $2,7,8$

The aims of this study were to examine long-term survival in a population based sample of SCI survivors in Great Britain, identify risk factors contributing to deaths and explore trends in cause of death over the decades following spinal cord injury. This investigation, covering 50 years of spinal cord injury experience, is the longest follow-up SCI survival study to date. Results are compared with SCI mortality data from the United States.

\section{Subjects and identification methods}

The inclusion criteria for this survival study selected individuals seen for initial treatment and rehabilitation within one year of injury at the two oldest spinal

Correspondence: HL Frankel injuries centres in Great Britain - the National Spinal Injuries Centre at Stoke Mandeville Hospital in Aylesbury, England, and the Regional Spinal Injuries Centre in Southport, England. Those included had to have sustained traumatic spinal cord injuries prior to January 11991 and survived at least 1 year following injury. Study eligibility was further limited to those individuals whose residence at the time of injury was within a specified 17 county catchment area of the two spinal centres. This geographic restriction helped ensure that the sample was population based, and also increased the likelihood that subjects utilized one of the two centres for their on-going follow-up care.

A review of the medical records from both centers confirmed that 3179 individuals met these study criteria. This included 835 individuals reported in a previous study ${ }^{7}$ and added 2344 for the current analysis. The demographic characteristics of this population are shown in Table 1. Since the study spans nearly five decades, demographic data are given for each decade and for the total population. Approximately $81 \%$ of this population are male and $19 \%$ female, which is similar to the gender distributions from the US National SCI Database $(82.2 \%$ and $17.8 \%)^{9}$. Age distributions at the time of injury are also shown in Table 1. Population based studies demonstrate that SCI occurs most frequently in young adults. ${ }^{10} \mathrm{~A}$ similar pattern was noted in this study, and the distribution closely mirrors age at injury patterns in the US. ${ }^{9}$ 
Table 1 Demographic characteristics by decade

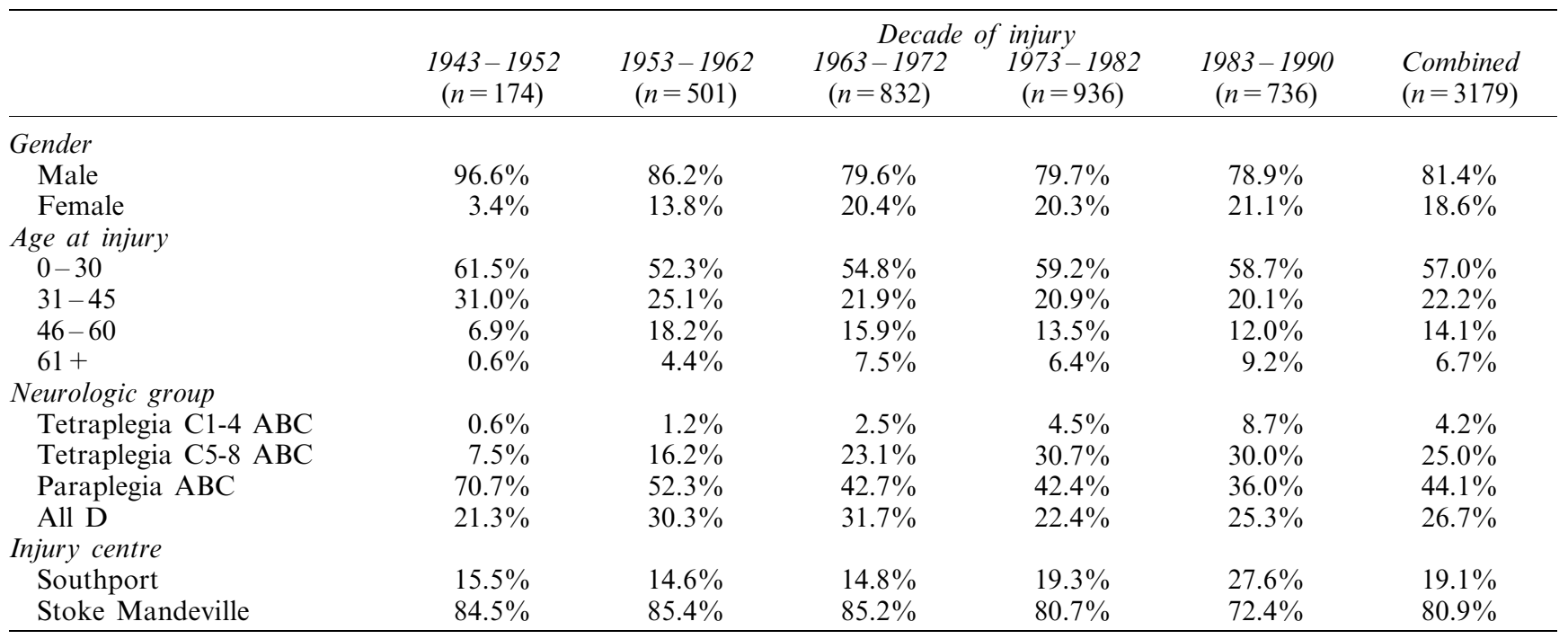

For the analyses, individuals were categorized into four neurologic groups, based on functional capabilities. Frankel ${ }^{11}$ classifications $\mathrm{A}, \mathrm{B}$ and $\mathrm{C}$ include individuals with little or no useful muscle power below their injury sites. Frankel D and $E$ indicate that individuals have useful or full recovery of muscles below their injury. Those with Frankel D or E classifications, whether they have injuries at the cervical, thoracic or lower levels, tend to have more similar functional abilities. In addition, those with tetraplegia were divided into 'high' and 'low' groupings, as their functional abilities are markedly different and previous research ${ }^{1}$ has shown significant differences in survival as well. Therefore, this study sample has been grouped as follows: tetraplegia $\mathrm{C} 1-\mathrm{C} 4 \mathrm{ABC}$; tetraplegia $\mathrm{C} 5-\mathrm{C} 8 \mathrm{ABC}$; paraplegia $\mathrm{ABC}$; and all D's (there were no individuals classified as Frankel $\mathrm{E}$ by the time of initial discharge in this study). The percentages of individuals in each of these groups are given in Table 1 .

In order to determine survival status, the records of the two spinal units were extensively reviewed. In all cases, the full name, date of birth, place of birth, last known address, death date (if applicable) and National Health Service identification numbers (when available) were extracted. These data were then submitted to the National Health Service Office of Population Censuses and Surveys (OPCS). ${ }^{12}$ In cases where death was already known or subsequently confirmed by the OPCS search, the OPCS was requested to furnish a copy of each individual's death certificate to verify the cause of death. To confirm survival of individuals presumed to be alive and not being routinely followed at the spinal centers, the OPCS was able to identify the Family Health Service Authority (FHSA) in which the individual was last known to be registered. A letter for each individual living in a particular FHSA was then sent to that FHSA for distribution to their respective family doctor. Each letter requested that the doctor contact the research team to confirm survival of each individual. These extensive follow-up procedures yielded a $92.3 \%$ success rate in identifying current survival status. The OPCS was unable to trace some individuals due to reasons as varied as institutionalization in mental health facilities, emigration from the United Kingdom, or non-registration with a family doctor. The survival status of these cases, who represent $7.7 \%$ of the study sample, could not be determined. However, these currently untraceable individuals are included in the following analyses, classified as having withdrawn from the study at the time of their last known date alive. This enables the follow-up period for which the individual was known to be alive to contribute to the survival experience.

\section{Mortality analysis}

\section{Comparison to general population}

Mortality rates of the SCI study population are compared to the general population by calculating Standardized Mortality Ratios (SMRs). SMR is defined as actual mortality in a study population divided by the expected mortality in the general population over an equivalent follow-up time period. Since mortality rates are based on gender, age and calendar year (1943-1992), the expected mortality is calculated by matching each SCI subject to the general population by these factors. Age and gender specific mortality rates for the general population were obtained from the Office of Population Censuses and Surveys. Expected survival over the entire follow-up interval was cumulated by multiplying the expected yearly survival probabilities over the follow-up interval in accordance with standard actuarial practices. ${ }^{13}$ Expected mortality over the entire follow-up period 
was then calculated as 1.0 minus the cumulated expected survival rate. For those calendar years in which the subject's follow-up did not include the full year, adjustments were made to the yearly survival probabilities to reflect the partial year mortality probability.

These individual survival probabilities were aggregated by neurologic group to yield group SMRs. An SMR of 1.0 indicates that the SCI group has identical survival to the general population. An SMR greater than 1.0 indicates that the mortality rate in the SCI group is greater than the general population. For example, an SMR of 2.0 suggests that mortality rate in the SCI population is twice that of the general population, while an SMR of 4.0 suggests that four times as many deaths occurred in the SCI population than expected in the general population.

Table 2 provides the SMRs by neurologic injury group and age group for the entire sample. Ninetyfive percent confidence intervals are given for each SMR.

Table 3 shows the SMRs by age and neurologic injury group for those subjects injured in 1973 or later. This table is provided to reflect the most recent mortality history, and allows direct comparison to the previously cited US study, since the same followup time frame and inclusion criteria of one year survival were used. ${ }^{1}$

Table 2 Standardized mortality ratios for injury years 1943-1990

\begin{tabular}{|c|c|c|c|c|c|c|c|}
\hline Injury group & $\begin{array}{l}\text { Age at } \\
\text { injury }\end{array}$ & $\begin{array}{c}\text { Number in } \\
\text { group }\end{array}$ & $\begin{array}{c}\text { Expected } \\
\text { dead }\end{array}$ & $\begin{array}{c}\text { Actual } \\
\text { dead }\end{array}$ & $S M R$ & $\begin{array}{c}\text { Lower } \\
95 \% C L\end{array}$ & $\begin{array}{c}\text { Upper } \\
95 \% C L\end{array}$ \\
\hline \multirow[t]{4}{*}{$\mathrm{C} 1-\mathrm{C} 4 \mathrm{ABC}$} & $0-30$ & 57 & 0.61 & 4 & 6.54 & 1.70 & 14.52 \\
\hline & $31-45$ & 23 & 0.60 & 3 & 5.03 & 0.95 & 12.34 \\
\hline & $46-60$ & 32 & 4.12 & 21 & 5.10 & 3.15 & 7.52 \\
\hline & $61+$ & 22 & 4.55 & 15 & 3.29 & 1.84 & 5.17 \\
\hline \multirow[t]{4}{*}{$\mathrm{C} 5-\mathrm{C} 8 \mathrm{ABC}$} & $0-30$ & 468 & 10.14 & 69 & 6.80 & 5.29 & 8.50 \\
\hline & $31-45$ & 156 & 10.80 & 56 & 5.19 & 3.92 & 6.63 \\
\hline & $46-60$ & 101 & 11.05 & 57 & 5.16 & 3.91 & 6.59 \\
\hline & $61+$ & 69 & 12.41 & 46 & 3.71 & 2.71 & 4.85 \\
\hline \multirow[t]{4}{*}{ Para ABC } & $0-30$ & 848 & 35.61 & 148 & 4.16 & 3.51 & 4.85 \\
\hline & $31-45$ & 346 & 40.31 & 131 & 3.25 & 2.72 & 3.83 \\
\hline & $46-60$ & 161 & 29.83 & 90 & 3.02 & 2.43 & 3.67 \\
\hline & $61+$ & 47 & 10.47 & 34 & 3.25 & 2.25 & 4.43 \\
\hline \multirow[t]{4}{*}{ All D } & $0-30$ & 438 & 15.49 & 45 & 2.91 & 2.12 & 3.82 \\
\hline & $31-45$ & 181 & 24.43 & 63 & 2.58 & 1.98 & 3.25 \\
\hline & $46-60$ & 155 & 40.98 & 78 & 1.90 & 1.50 & 2.35 \\
\hline & $61+$ & 75 & 30.04 & 49 & 1.63 & 1.21 & 2.12 \\
\hline
\end{tabular}

Table 3 Standardized mortality ratios for injury years 1973-1990

\begin{tabular}{lcccccccc}
\hline Injury group & $\begin{array}{c}\text { Age at } \\
\text { injury }\end{array}$ & $\begin{array}{c}\text { Number } \text { in } \\
\text { group }\end{array}$ & $\begin{array}{c}\text { Expected } \\
\text { dead }\end{array}$ & $\begin{array}{c}\text { Actual } \\
\text { dead }\end{array}$ & SMR & 95\% CL & $\begin{array}{c}\text { Upper } \\
\text { 95\% }\end{array}$ & $\begin{array}{c}\text { US } \\
\text { SMR }\end{array}$ \\
\hline C1-C4 ABC & $0-30$ & 53 & 0.38 & 3 & 7.84 & 1.48 & 19.22 & 10.94 \\
& $31-45$ & 21 & 0.57 & 1 & 1.77 & 0.00 & 6.93 & 9.78 \\
& $46-60$ & 17 & 1.65 & 8 & 4.86 & 2.08 & 8.81 & 5.24 \\
C5-C8 ABC & $61+$ & 15 & 2.45 & 10 & 4.08 & 1.94 & 7.00 & 3.07 \\
& $0-30$ & 294 & 2.87 & 24 & 8.37 & 5.35 & 12.05 & 5.07 \\
& $31-45$ & 97 & 2.76 & 17 & 6.15 & 3.57 & 9.42 & 6.30 \\
Para ABC & $46-60$ & 66 & 6.20 & 26 & 4.19 & 2.74 & 5.96 & 3.83 \\
& $61+$ & 51 & 8.51 & 30 & 3.53 & 2.38 & 4.90 & 3.07 \\
& $0-30$ & 411 & 4.13 & 13 & 3.14 & 1.67 & 5.09 & 3.86 \\
All D & $31-45$ & 152 & 5.59 & 17 & 3.04 & 1.77 & 4.66 & 3.74 \\
& $46-60$ & 72 & 9.57 & 21 & 2.20 & 1.36 & 3.23 & 1.96 \\
& $61+$ & 27 & 4.35 & 16 & 3.68 & 2.10 & 5.71 & 2.21 \\
& $0-30$ & 228 & 2.01 & 4 & 1.99 & 0.52 & 4.41 & 2.58 \\
& $31-45$ & 74 & 2.40 & 11 & 4.58 & 2.27 & 7.68 & 2.03 \\
& $46-60$ & 59 & 8.61 & 12 & 1.39 & 0.72 & 2.29 & 1.66 \\
\hline
\end{tabular}

*DeVivo MJ and Stover SL. 'Long-Term Survival and Causes of Death'. Chapter 14 in: Stover SL, DeLisa JA, Whiteneck GG, eds. Spinal Cord Injury: Clinical Outcomes from the Model Systems. Aspen Publishers, Inc., Gaithersburg MD, 1995 


\section{Predicted life expectancy}

SMRs can also be used to estimate the remaining years of life for an individual with SCI. Actuarial methods were employed to predict remaining years of life for the general population and SCI population. ${ }^{13}$ Yearly mortality probabilities were assigned using the gender and age specific mortality rates for 1992, the most recent year for which OPCS data was available. Each yearly mortality rate was multiplied by the appropriate age and injury group SMR to determine the annual predicted mortality for the group of interest. The SMRs based on injuries occurring in 1973 or later were used since they reflect the most recent mortality experience and are consistent with the methodology used in the US study. Annual survival probabilities were cumulated in the same manner as in the calculation of the SMRs resulting in the conditional probability of survival to a particular year given that the subject had survived over the previous years. Predicted life expectancy was calculated as the sum of the annual conditional survival probabilities up to the point where additional survival was negligible. Because the SMRs for the $\mathrm{C} 1-\mathrm{C} 4 \mathrm{ABC}$ and $\mathrm{C} 5-\mathrm{C} 8$ $\mathrm{ABC}$ groups were similar and the number of subjects in these groups were relatively small, it was decided to combine these groups resulting in SMRs of 8.31, 5.41, 4.33 and 3.65 for the age groups $0-30,31-45,46-60$ and $61+$ respectively. To overcome the instability of the SMRs, smoothing techniques were applied using a

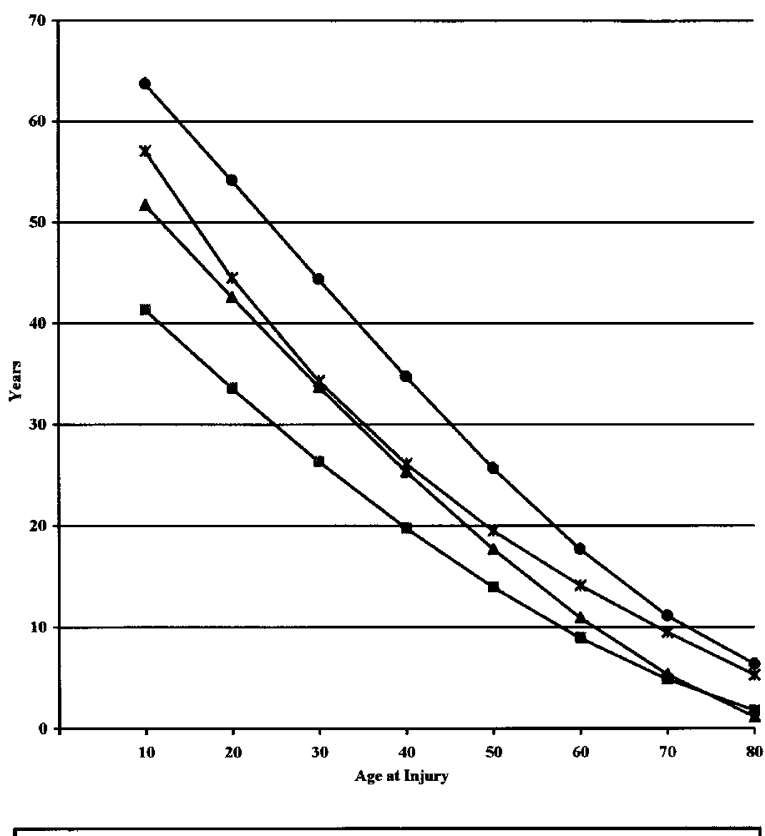

General Population $\rightarrow-$ Tetraplegia $\rightarrow-$ Paraplegia $\rightarrow-$ All D

Figure 1 Smoothed projected life expectancies for males based on SMRs since 1973 using 1992 mortality tables tetras combined 3rd degree polynomial regression to reduce variations attributable to the instability of the SMRs. Gender specific predicted life expectancies are plotted in Figures 1 and 2. Table 4 lists the smoothed values of remaining years of life.

\section{Cox regression}

Cox proportional hazards regression was performed to assess the influence of predictor variables (in the presence of other predictors) on survival. ${ }^{15}$ The main purpose of this analysis was to quantify the improvement in survival over the 50 year span of the study. Because the amount of follow-up for an individual is a function of the year the individual was injured, five subgroup analyses were performed to ensure consistency of the risk ratios over time. The first sub-analysis included all individuals and spanned the first 10 years of follow-up for each individual. The second subanalysis spanned the first 20 years of follow-up and excluded individuals injured in the most recent decade 1983-1990, since they were not eligible for a full 20 years of follow-up. The remaining sub-analyses were constructed in a similar manner comparing only those individuals with equivalent follow-up times. The results of these sub-analyses exhibited consistent risk ratios over time indicating that a single analysis spanning all 50 years of follow-up was appropriate and that the assumptions of proportional hazards over time were

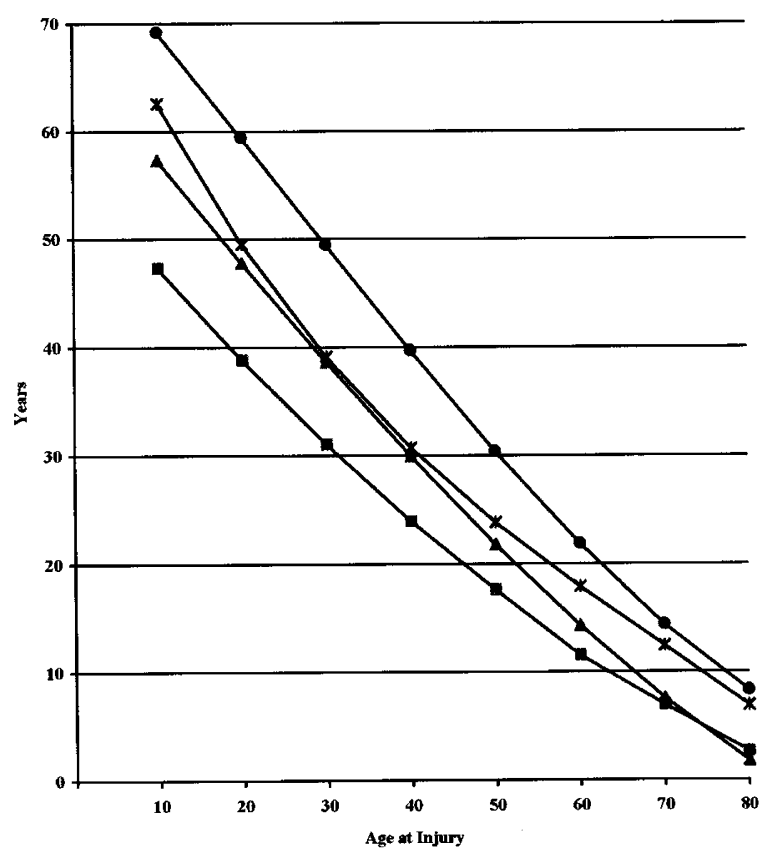

$\rightarrow-$ General Population $\rightarrow-$ Tetraplegia $\rightarrow-$ Paraplegia $\rightarrow *-$ All D

Figure 2 Smoothed projected life expectancies for females based on SMRs since 1973 using 1992 mortality tables tetras combined 
reasonable. The results of this analysis are shown in Table 5.

\section{Causes of death}

Over the time span of the study, causes of death have demonstrated changing trends. The leading causes for the entire time period, the first three decades of injury, and the final two decades of injury are shown in their respective rank orders in Table 6 . There has been a shift away from the predomination of traditional urinary system causes of death in the early years of SCI rehabilitation and follow-up. Pneumonia, influen$\mathrm{za}$, and other respiratory diseases lead in the latter time period, however, it should be noted that the term 'pneumonia' may be indicated on death certificates in the absence of an autopsy and another definitive cause of death. Furthermore, injuries (including suicide) account for a larger proportion of the deaths among those injured in the latter two decades.

To determine which factors are predictive of specific causes of death, the three leading causes of death were subjected to Cox proportional hazards regression. Tables 7, 8 and 9 list the results for respiratory, urinary system and heart disease. For each of these analyses, individuals who had died from a cause other than that for which the regression is calculated are treated as censored observations (alive).

Table 4 Smoothed projected life expectancies

\begin{tabular}{|c|c|c|c|c|c|c|c|c|}
\hline \multirow[b]{2}{*}{$\begin{array}{l}\text { Age at } \\
\text { injury }\end{array}$} & \multicolumn{3}{|c|}{ Male } & & \multicolumn{4}{|c|}{ Female } \\
\hline & $\begin{array}{c}\text { General } \\
\text { population }\end{array}$ & $\begin{array}{l}\text { Tetra } \\
\text { ABC }\end{array}$ & $\begin{array}{l}\text { Para } \\
A B C\end{array}$ & All $D$ & $\begin{array}{c}\text { General } \\
\text { population }\end{array}$ & $\begin{array}{l}\text { Tetra } \\
A B C\end{array}$ & $\begin{array}{l}\text { Para } \\
A B C\end{array}$ & All D \\
\hline 5 & 68.31 & 45.41 & 56.30 & 64.33 & 73.87 & 51.84 & 62.14 & 70.19 \\
\hline 10 & 63.73 & 41.34 & 57.10 & 57.05 & 69.15 & 47.29 & 57.30 & 62.56 \\
\hline 15 & 59.00 & 37.39 & 47.12 & 50.45 & 64.31 & 42.94 & 52.52 & 55.70 \\
\hline 20 & 54.16 & 33.57 & 42.58 & 44.50 & 59.39 & 38.77 & 47.80 & 49.55 \\
\hline 25 & 49.26 & 29.88 & 38.10 & 39.14 & 54.43 & 34.79 & 43.17 & 44.04 \\
\hline 30 & 44.36 & 26.34 & 33.72 & 34.33 & 49.47 & 30.99 & 38.64 & 39.11 \\
\hline 35 & 39.50 & 22.96 & 29.46 & 30.01 & 44.55 & 27.38 & 34.22 & 34.69 \\
\hline 40 & 34.74 & 19.75 & 25.35 & 26.13 & 39.71 & 23.94 & 29.93 & 30.71 \\
\hline 45 & 30.12 & 16.74 & 21.41 & 22.66 & 34.98 & 20.69 & 25.78 & 27.11 \\
\hline 50 & 25.71 & 13.91 & 17.68 & 19.53 & 30.40 & 17.60 & 21.78 & 23.82 \\
\hline 55 & 21.56 & 11.30 & 14.18 & 16.70 & 26.01 & 14.69 & 17.94 & 20.78 \\
\hline 60 & 17.70 & 8.90 & 10.94 & 14.11 & 21.86 & 11.95 & 14.29 & 17.91 \\
\hline 65 & 14.20 & 6.74 & 7.99 & 11.73 & 17.97 & 9.37 & 10.84 & 15.15 \\
\hline 70 & 11.11 & 4.83 & 5.35 & 9.50 & 14.39 & 6.96 & 7.59 & 12.44 \\
\hline 75 & 8.47 & 3.17 & 3.05 & 7.37 & 11.16 & 4.72 & 4.56 & 9.71 \\
\hline 80 & 6.35 & 1.77 & 1.11 & 5.29 & 8.31 & 2.63 & 1.77 & 6.89 \\
\hline
\end{tabular}

Table 5 Cox regression for mortality (1943-1990)

\begin{tabular}{|c|c|c|c|c|c|c|c|c|}
\hline Effect & \multicolumn{2}{|c|}{ Risk ratio } & \multicolumn{2}{|c|}{ Lower $95 \% C L$} & \multicolumn{2}{|c|}{ Upper $95 \% C L$} & \multicolumn{2}{|c|}{$P$-value } \\
\hline \multicolumn{9}{|l|}{ Gender } \\
\hline Male & \multirow{2}{*}{\multicolumn{2}{|c|}{$\begin{array}{l}1.23 \\
\mathbf{1 . 0 0}\end{array}$}} & \multirow{2}{*}{\multicolumn{2}{|c|}{1.03}} & \multicolumn{2}{|c|}{1.47} & \multicolumn{2}{|c|}{0.0226} \\
\hline Female & & & & & & & & \\
\hline \multicolumn{9}{|l|}{ Neurologic Group } \\
\hline Tetraplegia ABC* & \multicolumn{2}{|c|}{2.22} & \multicolumn{2}{|c|}{1.85} & \multicolumn{2}{|c|}{2.66} & \multicolumn{2}{|c|}{0.0001} \\
\hline Paraplegia ABC & \multicolumn{2}{|c|}{1.46} & \multirow{2}{*}{\multicolumn{2}{|c|}{1.23}} & \multirow{2}{*}{\multicolumn{2}{|c|}{1.73}} & \multicolumn{2}{|c|}{0.0001} \\
\hline All D & \multicolumn{2}{|c|}{1.00} & & & & & \multirow{2}{*}{\multicolumn{2}{|c|}{0.0001}} \\
\hline Age at Injury $(\uparrow$ risk/ & & & \multicolumn{2}{|c|}{1.07} & \multicolumn{2}{|c|}{1.08} & & \\
\hline Decade of injury $\dagger$ & Stoke & S'port & Stoke & S'port & Stoke & S'port & Stoke & S'port \\
\hline $1943-1952$ & 3.49 & 5.59 & 2.41 & 3.42 & 5.04 & 9.13 & 0.0001 & 0.0001 \\
\hline $1953-1962$ & 2.09 & 3.08 & 1.51 & 2.08 & 2.89 & 4.57 & 0.0001 & 0.0001 \\
\hline $1963-1972$ & \multicolumn{2}{|c|}{1.90} & \multicolumn{2}{|c|}{1.40} & \multicolumn{2}{|c|}{2.58} & \multicolumn{2}{|c|}{0.0001} \\
\hline $1973-1982$ & \multicolumn{2}{|c|}{1.50} & \multirow{2}{*}{\multicolumn{2}{|c|}{1.09}} & \multirow{2}{*}{\multicolumn{2}{|c|}{2.05}} & \multirow{2}{*}{\multicolumn{2}{|c|}{0.0116}} \\
\hline $1983-1990$ & & & & & & & & \\
\hline
\end{tabular}

*Analysis of high tetraplegia (C1-C4 ABC) versus low tetraplegia (C5-C8 ABC) showed no significant difference in mortality ( $p$ $0.7763)$ and were therefore combined. The risk ratios for high and low tetraplegia compared to the Frankel Ds were 2.13 and 2.24 respectively

$\dagger$ Differences in the two SCI centres existed only in the first two decades of injury 
Table 6 Causes of death

\begin{tabular}{|c|c|c|c|c|c|c|}
\hline \multirow[b]{2}{*}{ Cause of death } & \multicolumn{2}{|c|}{ All years of injury } & \multicolumn{2}{|c|}{$1943-1972$ injuries } & \multicolumn{2}{|c|}{$1973-1990$ injuries } \\
\hline & $\mathrm{n}=886(\%)$ & Rank & $\mathrm{n}=660(\%)$ & Rank & $\mathrm{n}=226(\%)$ & Rank \\
\hline Pneumonia/influenza/other respiratory & $205(23)$ & 1 & $129(19)$ & 3 & $76(34)$ & 1 \\
\hline Urinary system & $169(19)$ & 2 & $148(22)$ & 1 & $21(9)$ & 4 \\
\hline Ischaemic/non-ischaemic heart disease & $161(18)$ & 3 & $133(20)$ & 2 & $28(12)$ & 2 \\
\hline Cancer & $90(10)$ & 4 & $71(11)$ & 4 & $19(8)$ & 6 \\
\hline Cerebrovascular & $44(5)$ & 7 & $32(5)$ & 7 & $12(5)$ & 8 \\
\hline Digestive system & $32(4)$ & 9 & $17(3)$ & 9 & $15(7)$ & 7 \\
\hline Injuries (including suicide) & $57(6)$ & 6 & $35(5)$ & 6 & $22(10)$ & 3 \\
\hline Septicaemia & $33(4)$ & 8 & $23(3)$ & 8 & $10(4)$ & 9 \\
\hline Arteries/pulmonary circulation & $20(2)$ & 10 & $17(3)$ & 9 & $3(1)$ & 10 \\
\hline Other and ill-defined causes & $75(8)$ & 5 & $55(8)$ & 5 & $20(9)$ & 5 \\
\hline
\end{tabular}

Table 7 Cox regression for pneumonia, influenza and other respiratory disease

\begin{tabular}{|c|c|c|c|c|}
\hline Effect & Risk ratio & $\begin{array}{l}\text { Lower } \\
95 \% \text { CL }\end{array}$ & $\begin{array}{c}\text { Upper } \\
95 \% \text { CL }\end{array}$ & $\mathrm{P}$-value \\
\hline \multicolumn{5}{|l|}{ Neurologic Group } \\
\hline Tetraplegia ABC & 4.67 & 3.16 & 6.90 & 0.0001 \\
\hline Paraplegia ABC & 2.07 & 1.37 & 3.12 & 0.0005 \\
\hline All D & 1.00 & & & \\
\hline \multicolumn{5}{|l|}{ Age at injury } \\
\hline $0-30$ & 1.00 & & & \\
\hline $31-45$ & 4.87 & 3.08 & 7.69 & 0.0001 \\
\hline $46-60$ & 19.04 & 12.28 & 29.51 & 0.0001 \\
\hline $61+$ & 45.98 & 28.75 & 73.53 & 0.0001 \\
\hline
\end{tabular}

Table 8 Cox regression for urinary system disease

\begin{tabular}{lcccc}
\hline & \multicolumn{5}{c}{ Lower } & \multicolumn{2}{c}{ Upper } \\
Effect & Risk ratio $95 \%$ CL & $95 \%$ & CL & P-value \\
\hline $\begin{array}{l}\text { Gender } \\
\quad \text { Male }\end{array}$ & 1.75 & 1.05 & 2.94 & 0.0332 \\
$\quad$ Female & $\mathbf{1 . 0 0}$ & & & \\
$\begin{array}{l}\text { Neurologic group } \\
\quad \text { Tetraplegia ABC }\end{array}$ & 4.35 & 2.69 & 7.03 & 0.0001 \\
$\quad \begin{array}{l}\text { Paraplegia ABC } \\
\text { All D }\end{array}$ & 2.20 & 1.41 & 3.44 & 0.0005 \\
$\begin{array}{l}\text { Age at injury } \\
\quad(\uparrow \text { risk/year of age) }\end{array}$ & 1.05 & 1.04 & 1.06 & 0.0001 \\
$\begin{array}{l}\text { SCI Centre } \\
\quad \text { Stoke Mandeville }\end{array}$ & 0.59 & 0.41 & 0.84 & 0.0035 \\
$\quad$ Southport & $\mathbf{1 . 0 0}$ & & & \\
$\begin{array}{l}\text { Decade of injury } \\
\quad(\uparrow \text { risk/earlier decade) }\end{array}$ & 2.22 & 1.88 & 2.62 & 0.0001 \\
\hline
\end{tabular}

Neurologic injury level and age at injury are significant predictors for pneumonia, influenza and other respiratory diseases. Individuals with tetraplegia and paraplegia are 4.67 and 2.07 times more likely to die from these causes than individuals classified as Frankel D injured at the same age. Since the risk associated with age at injury is not constant from one age to the next, age at injury was divided into four
Table 9 Cox regression for heart disease

\begin{tabular}{lrrrr}
\hline & \multicolumn{5}{c}{$\begin{array}{c}\text { Lower } \\
\text { Effect }\end{array}$} & Risk ratio $95 \%$ & CL95\% & CL P-value \\
\hline $\begin{array}{l}\text { Gender } \\
\quad \text { Male }\end{array}$ & 1.63 & 1.03 & 2.63 & 0.0374 \\
$\quad$ Female & $\mathbf{1 . 0 0}$ & & & \\
Age at injury & & & & \\
$\quad 0-30$ & $\mathbf{1 . 0 0}$ & & & \\
$31-45$ & 3.04 & 1.99 & 4.66 & 0.0001 \\
$46-60$ & 10.18 & 6.50 & 15.93 & 0.0001 \\
$\quad 61+$ & 39.00 & 24.00 & 63.38 & 0.0001 \\
$\begin{array}{l}\text { Decade of injury } \\
\quad(\uparrow \text { risk/earlier decade) }\end{array}$ & 1.37 & 1.15 & 1.64 & 0.0006 \\
\hline
\end{tabular}

categories. Individuals injured at ages $31-45$ are 4.87 times more likely to die from these causes than those injured at age 30 and under. The risk is almost quadrupled for those injured at ages 46-60 compared to those aged $31-45$ of the same neurologic injury level. The group with the highest risk of dying from respiratory diseases are those individuals injured at age 61 or older. Their risk is approximately 46 times greater than those injured at age 30 or younger. The effect of injury year was not statistically significant, suggesting that the risk of dying from these causes has remained relatively constant over the last 50 years.

With regard to urinary diseases, males are $75 \%$ more likely to die of urinary system diseases than females. Neurologic injury level is also predictive of urinary system diseases; those with tetraplegia and paraplegia are 4.35 and 2.20 times more likely to die from these causes than individuals classified as Frankel D. The risk associated with age at injury is 5\% higher per year. This equates to a $67 \%$ increased risk over a ten year period indicating that individuals injured at older ages are more at risk of dying of urinary system diseases. The risk associated with each earlier decade of injury is 2.2 times greater than the following decade. This equates to a risk of 1.00 for the reference decade 1983-1990, 2.20 for those injured in $1973-1982,4.92$ for $1963-1972,10.92$ for $1953-$ 1962 and 24.22 for $1943-1952$. In other words, the 
risk of dying from urinary system diseases was more than halved in each subsequent decade. A protective effect is associated with Stoke Mandeville; the risk of dying of urinary system diseases is $41 \%$ lower than those treated at Southport. Data regarding differences in method of bladder management at the two centres were not available for this study.

The results of the Cox regression for death due to heart disease shows males have a $64 \%$ greater risk of dying than females injured at the same age and in the same decade. Age at injury is a significant predictor of heart disease deaths showing that individuals injured at older ages are more at risk. Individuals injured at ages $31-45$ are 3.04 times more likely than those injured at age 30 or younger. Similarly, those injured at ages $46-60$ and $60+$ are 10.18 and 39.00 times more likely to die of heart disease than those aged 30 and younger. The risk for individuals injured in each earlier decade is $37 \%$ higher than for the following decade. Using 1983-1990 as the reference decade yields the following risk ratios: 1.37 for $1973-1982$, 1.88 for $1963-1972,2.58$ for $1953-1962$ and 3.54 for $1943-1952$.

\section{Discussion}

With improved emergency medical techniques at the scene of automobile crashes and industrial accidents, immediate survival for people with SCI has improved, thus enabling more indidivuals to be transferred for rehabilitation to specialized SCI treatment centres. In addition, survival for the first year has improved due to advances in medical care over the past 50 years. However, even with improved emergency medical treatment and sophisticated rehabilitation, the general mortality rates of individuals with SCI exceed those of an age-matched non-disabled population. There are slight improvements when evaluating SMRs in the last two decades $(1973-1991)$ and British ratios are essentially comparable to US data.

In this study, the slight increase in mortality of the C5-C8 ABC group compared to the $\mathrm{C} 1-\mathrm{C} 4 \mathrm{ABC}$ group may be explained by the inclusion criteria requiring that a person had survived the first year post injury, and that the vast majority in the latter group $(90 \%)$ are individuals with C-4 level injuries. Furthermore, the $\mathrm{C} 1-\mathrm{C} 4 \mathrm{ABC}$ group is, as expected, considerably smaller than the other neurologic groups, partly due to the increased mortality for individuals with high cervical lesions during their first year following injury. The findings would seem to indicate that there is no difference in the mortality rates of the $\mathrm{C} 1-\mathrm{C} 4$ and $\mathrm{C} 5-\mathrm{C} 8 \mathrm{ABC}$ injury groups, given the individual has survived the first year post injury.

The further decreased sample size of the $\mathrm{C} 1-\mathrm{C} 4$ sub-group with injury years 1973-1991 results in less stability of the SMRs. In particular, the extremely low SMR for those aged $31-45$ is most likely attributable to the smaller number of subjects $(n=21)$ comprising this group. Because of this small group size, the SMR is very sensitive to the actual number of deaths. For example, if two individuals in the $31-45$ year old $\mathrm{Cl}-$ 4 group had died, the SMR would be 3.51 ; three deaths would have resulted in an SMR of 5.26.

In comparison to the US study, the SMRs are equivalent (within 95\% confidence limits) for all cells with the following exceptions. The SMR for the $\mathrm{Cl}-$ C4 ABC neurologic group aged $31-45$ is significantly lower than that reported in the US study and, as discussed previously, could be explained by the small number of individuals in that group. The SMRs for the C5-C8 ABC group aged $0-30$ and Frankel D group aged $31-45$ are significantly higher than the US SMRs.

The effects of gender, neurologic injury classification, age at injury and decade of injury are significant determinants of mortality. Males are $23 \%$ more likely to die than females of the same injury age, injury year, neurologic injury level and SCI treatment centre. While analysis of high tetraplegia $(\mathrm{C} 1-4 \mathrm{ABC})$ versus low tetraplegia (C5-8 ABC) shows no significant difference in mortality, individuals with tetraplegia and paraplegia are 2.22 and 1.46 times more likely to die than those with very incomplete injuries, Frankel D classification, controlling for other variables in the model. Furthermore, for each year of advancing age at injury, an individual is $7 \%$ more likely to die than if he or she was injured 'a year younger'. This translates to almost a twofold increase in mortality risk with each advancing decade of age at injury. That is, individuals with SCI have better survival outcomes if they are injured at earlier ages. Using the most recent decade of injury $(1983-1990)$ as the reference decade, individuals injured in the previous decade were 1.50 times more likely to die than had they been injured in 1983-1990. This represents a considerable improvement in survival in the last 10 years. Comparing the first decade of injury $(1943-1952)$ to the most recent represents a reduction in mortality of $71 \%$ and $82 \%$ over 50 years, depending on the centre in which the individual was treated.

It should be noted that the Cox regression only compares subjects in the study population and does not make inferences to the general population. Therefore, it is difficult to identify the effects of gender, age and decade experienced by the general population. Using gender as an example, in the general population males have poorer survival than females of the same age. The Cox regression does not distinguish between the magnitude of the effect experienced by the general population and the incremental effect experienced by the SCI population. Reporting cause-specific SMRs could be attempted, however, due to the small number of deaths in the study, further breakdown into age, duration of injury, gender and neurologic groups would result in unstable SMRs.

The cause-specific Cox regressions also warrant further explanation. In particular, neurologic status was not a significant predictor of heart disease, while it was a risk factor for both urinary and respiratory 
diseases. Due to the low incidence of both ischaemic and non-ischaemic conditions, these were combined, and it is possible that this resulted in negating the effect of neurologic status. For example, if ischaemic heart disease has a greater impact on individuals with more neurologically incomplete injuries and nonischaemic conditions are experienced more frequently by those with complete injuries, neurologic status would not be a significant predictor of death due to heart disease.

It would appear that respiratory and injury related deaths are on the increase in the latter decades. In fact, the actual death rates for these causes are declining, and can be verified by calculating the cause-specific mortality rates (deaths/ $\mathrm{N}$ at risk) for each time period. Different exposure times for those in the early versus the latter decades may also account for the apparent shifting pattern in causes of death. As previously demonstrated, the Cox regression for respiratory deaths does not show duration of injury to be a predictive factor.

Life expectancy is important data to both clinicians, SCI survivors, and insurance companies. Accurate assessments of projected life expectancy following injury are difficult to make, and must take into consideration several intangible factors, such as family history, potential health problems, availability of appropriate and adequate health care services, and the every day risks of further injury or death due to accidents or illness, faced by all individuals. In this investigation, differences in the age and gender distributions that exist across the neurologic injury groups are not taken into consideration in the computation of life expectancies. For example, there are more young males in the group with high tetraplegia and more older females in the group with paraplegia.

The SMRs for the individuals with tetraplegia $\mathrm{C} 1-$ $4 \mathrm{ABC}$ and life expectancy curves for the group with tetraplegia must be interpreted with caution. These data contain very few cases of individuals who may be dependent on mechanical respiration, and the SMRs are likely to be low estimates. In addition, the life expectancies for this group are substantially more optimistic than what both the available literature ${ }^{16}$ and clinical experience indicate for individuals requiring the use of mechanical respiration.

Caution also should be exercised in interpreting the predicted life expectancies. An assumption that mortality in the general population will remain constant in the future is inherent in the calculation of life expectancies since they are based solely on 1992 mortality data. The figures also do not incorporate the possibility of any current and future medical advances that would improve the survival of individuals with SCI. In addition, gender specific SMRs were not calculated due to limited size of the study population. Although gender specific life expectancies are given, they are based on SMRs that ignore gender (as there were too few women in the study sample to calculate accurate SMRs) and are instead based on gender specific mortality rates in the general population. The analyses were performed for this study to allow comparison to the US data. ${ }^{1}$ However, earlier research by the authors ${ }^{7}$ with a smaller sample demonstrated that SMRs should not be held constant over time as they actually decrease with duration of injury and age. Further analysis of this larger sample is planned which will incorporate both age and duration of injury in calculating mortality ratios to determine life expectancy.

Finally, the lack of differences in mortality rates between individuals with $\mathrm{Cl}-4$ tetraplegia and those with $\mathrm{C} 5-8$ tetraplegia are inconsistent with clinical experience. Further analysis examining the effect of different neurologic classification schemes for mortality risk analysis appears warranted. In fact, the authors have conducted additional research to address this issue. ${ }^{17}$

The present study suggests that the outlook for longer life expectancy following SCI is improving with each passing decade. Future mortality research to evaluate further changes as individuals survive into their fourth, fifth and later decades post-injury will be necessary to identify continued differences from the general population and changing patterns in causes of death.

\section{Acknowledgements}

This study was supported in part by the National Institute on Disability and Rehabilitation Research grant \#H133. G90010. The authors wish to thank the Office of Population Censuses and Surveys for their cooperation and assistance in tracing study participants, identifying survival status, and providing general population comparative data.

\section{References}

1 DeVivo MJ, Stover SL. Long-term survival and causes of death. In: Stover SL, DeLisa JA, Whiteneck GG (eds). Spinal Cord Injury: Clinical Outcomes from the Model Systems. Aspen: Gaithersburg MD 1995, pp 289-316.

2 Samsa GP, Patrick CH, Feussner JR. Long-term survival of veterans with traumatic spinal cord injury. Arch Neurol 1993; 50: $909-914$

3 Hackler RH. A 25-year prospective mortality study in the spinal cord injured patient: comparison with the long-term living paraplegic. J Urology 1977; 117: 486-488.

4 Kiwerski J, Weiss M, Chrostowska T. Analysis of mortality of patients after cervical spine trauma. Paraplegia 1981; 19: 347 351.

5 Snedon DG, Bedbrook G. Survival following traumatic tetraplegia. Paraplegia 1982; 20: $201-207$.

6 Minaire $\mathrm{P}$ et al. Life expectancy following spinal cord injury: a ten-years survey in the Rhône-Alpes region. Paraplegia 1983; 21: $11-15$.

7 Whiteneck GG et al. Mortality, morbidity and psychosocial outcomes of persons spinal cord injured more than 20 years ago. Paraplegia 1992; 30: 617-630.

8 Geisler WO, Jousse AT, Wynne-Jones M, Breithaupt D. Survival in traumatic spinal cord injury. Paraplegia 1983; 21: $364-373$. 
9 Go BK, DeVivo MJ, Richards JS. The epidemiology of spinal cord injury. In: Stover SL, DeLisa JA, Whiteneck GG (eds). Spinal Cord Injury: Clinical Outcomes from the Model Systems. Aspen: Gaithersburg MD 1995, pp 21-55.

10 Gerhart KA. Spinal cord injury outcomes in a population-based sample. J Trauma 1991; 31: 1529-1535.

11 Frankel $\mathrm{H}$ et al. The value of postural reduction in the initial management of closed injuries to the spine with paraplegia and tetraplegia. Paraplegia 1969; 7: 179-192.

12 Office of Population Censuses and Surveys. OPCS historic population file, 1901-1992 including all ICD-9 revisions. Computer diskettes, 1994.

13 Smart CN, Sanders CR. The costs of motor vehicle related SCI. Insurance Institute for Highway Safety: 1976 Washington DC.
14 Kelsey JL, Thompson WD, Evans AS. Methods in Observational Epidemiology. Oxford University Press: New York 1986, pp $128-147$.

15 Cox D, Oakes D. Analysis of Survival Data. Chapman and Hall: London 1990.

16 DeVivo MJ, Ivie CS. Life expectancy of ventilator-dependent persons with spinal cord injuries. Chest 1995; 108: 226-232.

17 Coll J, Frankel H, Charlifue S, Whiteneck G. Evaluating neurologic group homogeneity in assessing mortality risk for people with spinal cord injuries. Accepted for publication, Spinal Cord. 